\title{
Corruption in Procurement and Public Purchase
}

\author{
Emmanuelle Auriol ${ }^{1}$
}

October 28, 2005

Abstract: The paper studies capture and extortion in public purchase. It shows that capture yields a dead-weight loss while extortion does not. Based on the calibration of the model the total cost of capture is between 1.2 and 2.88 times the amount of the bribes. The theoretical analysis focuses on capture fight. The legal framework that emerges from the normative analysis involves open tender for larger purchases and no monitoring for the smaller ones. The rule is independent of a country's characteristics. Large public purchases should hence be ruled by international legislation. For markets of medium range national legislation differs. When susceptibility to corruption rises, there is a shift from the capture to the extortion regime.

JEL Classification Numbers: D73, D82, H57, K42.

Keywords: capture, extortion, procurement, public purchase, corruption dead-weight loss.

\footnotetext{
${ }^{1}$ ARQADE and IDEI, Place Anatole-France, 31042 Toulouse cedex, France, email: eauriol@cict.fr I thank Jean-Pierre Florens, Jean-Jacques Laffont, Jean Tirole, Colin Campbell, the participants of the 7th Jerusalem summer school in economic theory and of the EEA/ESEM 96 meetings for their helpful criticisms and comments on an early version of the paper. I am also very grateful to the participants of the first International Public Procurement Conference, Florida 2004, for helping me fine tune the model calibration. I am also endebted to Marie-Noele Bonnes for helping me with the English. Finally the paper has greatly benefited from two thorough referee and editor reports. I am grateful for the resulting improvements. Any remaining errors are mine.
} 


\section{Introduction}

Government procurement of goods and services represents more than $18 \%$ of the world GDP. ${ }^{1}$ For year 2002 this yields an estimate of USD 5.8 trillion. Despite the amounts at stake, tax-payers' ability and incentives to monitor public purchases are weak. Corruption is thus a major problem. The OECD Antibribery Convention, which came into force in February 1999, has apparently failed to cure it. It has resulted in only a handful of investigations and no conviction in the 35 signatory countries. In a study conducted by Transparency International (TI) to build its second Bribe Payers Index of leading exporting countries, in 2002, $60 \%$ of the respondents claimed that corruption in international business had increased or remained the same. When the respondents were asked to identify the business sectors in which bribery most commonly occurred, they said first public works contracts and construction, followed by the arms and defense industry. These are also the sectors where the biggest bribes are likely to be paid. ${ }^{2}$ Anecdotal evidences support the survey results. ${ }^{3}$ According to an ongoing research at the World Bank, the total amount of bribery for public procurement can hence be estimated in the vicinity of USD 200 billion per year. ${ }^{4}$ That is, approximately $3.5 \%$ of the world procurement spending. Assuming this figure is accurate, it represents only one part of the overall cost of corruption because corruption usually involves allocative inefficiency on top of the bribes. Since in practice nobody knows what would have been the final cost of the purchase if the most

\footnotetext{
${ }^{1}$ The OECD Trade Committee covering 130 countries estimates that the size of all levels of government procurement markets (i.e., consumption and investment expenditure) expressed as a percentage of 1998 GDP data is $18.42 \%$ (see OECD 2002). For the OECD countries as a whole the ratio is $19.96 \%$ (or USD 4733 billion) and for the non-OECD countries it is estimated at $14.48 \%$ (or USD 816 billion).

${ }^{2}$ For more on the survey see www.transparency.org/surveys/index.html\#bpi.

${ }^{3}$ For instance, the US group Lockheed was condemned to pay USD 24,8 million in fine for bribing a member of the Egyptian Popular Assembly to sell three C130 cargo airplanes (Le Monde 1995).

${ }^{4}$ For comments on the study see at the World Bank web page "Six questions on the cost of corruption" with Daniel Kaufmann.
} 
efficient supplier, rather than the biggest briber, had won the tender, it is not possible to estimate the real cost of corruption with classical survey techniques. The paper proposes a theoretical approach based on classical procurement theory to study the effect of corruption on the purchase cost. It distinguishes two forms of corruption.

Capture occurs when a firm bribes a public official to obtain a trading advantage. This corresponds to 'active bribery' as termed in the OECD Convention. On the other hand, extortion occurs when a firm complies with a demand for a bribe to avoid being excluded from trade. This type of bribes is referred to as 'facilitation payments' by international legislation. The paper shows that the two forms of corruption are not equivalent in terms of the cost they impose on the tax-payers. Capture, which obstructs allocative efficiency, yields a dead-weight loss; extortion does not. The paper illustrates the result by computing the tax-payers' loss. It relies on data on federal US procurement and on e-procurement to calibrate the capture dead-weight loss. According to the computation the total capture cost represents between 1.2 and 2.88 times the amount of the bribes. If the USD 200 billion figure is accurate, in 2002 the tax-payers should be willing to allocate at least USD 240 billion worldwide to fight capture.

The paper studies then how incentives and rules for decision should be set to respond to the capture threat. First, public purchasers should receive incentive payments to resist capture. The paper shows that the bonuses increase with market size so that achieving zero capture level is not efficient. Contrary to conventional wisdom, it is then better to have few markets affected by capture with high bribes rather than a generalized system of capture with a smaller level of bribes. Concentration minimizes the total capture deadweight loss. Subsequently the paper derives the optimal delegation scheme integrating 
the cost of the incentive payment. The legal framework that emerges from the theoretical analysis involves open tender for larger purchases, and no monitoring for smaller ones. The rule is independent of a country's characteristics. Fighting capture in large purchases then requires to develop international agreements, such as the Government Procurement Agreement (GPA). For markets of medium range, national legislation may differ because the optimal rule depends on a country's characteristics. Static comparative analysis hence shows that when a society's susceptibility to corruption rises, there is a shift from the costly capture regime to the extortion regime in which no monetary incentives are needed. This result seems especially relevant for developing countries where the government budget constraint is tight. In poor countries plagued with corruption, corruption in public purchase runs high and takes the extreme form of extortion. This helps to explain why the bribes paid to foreign public officials used to be tax deductible in OECD countries: The firms wanted the "commissions" to be acknowledged as a cost. ${ }^{5}$ The problem is that national legislation never drew the line between facilitation payments and other bribes. The paper shows that there should be a clear legal distinction between the two.

The issue of collusion in organizations within the agency theoretical approach was first raised by Tirole (1986) in a principal-supervisor-agent model. In this paper he derived a 'collusion-proofness principle', showing that any feasible payoff to the principal can be achieved by a contract which does not induce collusion between the agent and the supervisor. This seminal framework has since been used to study the impact of collusion in different contexts. ${ }^{6}$ The main results of this literature is that to fight collusion, it is

\footnotetext{
${ }^{5}$ In 1997, bribes paid to foreign officials were still tax deductible in Australia, Austria, Belgium, Iceland, Luxemburg, the Netherlands, New Zealand, and Switzerland.

${ }^{6}$ See for instance Laffont and Tirole (1993), Carillo (2000), Hindriks \& al (1999), Campbell (1996)).
} 
optimal, first, to change the agent's contract in order to lower the benefit of collusion, and, second, to reduce the supervisor's discretion. One concern with the collusion-proofness principle is that it is not robust if one relaxes the assumption that the susceptibility to corruption of the supervisor is common knowledge. Kofman and Lawarrée (1996) and Strausz (1998) hence show that under asymmetric information it is optimal to tolerate some corruption. ${ }^{7}$ Another concern with Tirole (1986) framework is that it focuses on mutually beneficial agreements between the supervisor and the agent. As stressed by the literature on blackmail (see Mogiljanski (1994), Konrad and Skaperdas (1997) and Leppamaki (2000)) extortion exists in practice. The present paper which combines Tirole (1986) framework with the assumption that the integrity of the supervisor is not observable, considers both capture and extortion.

The paper is organized as follows: Section 2 sets up the model. Section 3 derives the optimal contracts under the assumption that the delegate is incorruptible. Section 4 considers the possibility of corruption. Section 5 proposes a calibration of the capture cost. Our main findings are summarized in Section 6.

\section{The model}

As in Tirole (1986) the paper considers a three-tier hierarchy: principal, delegate, firms. All the players are assumed to be risk neutral. The principal (i.e. the tax-payers), conventionally a 'he', wants to acquire a commodity or a service in the best possible conditions. He entrusts the responsibility of the acquisition to a delegate (e.g, a public servant or a public representative), conventionally a 'she'. The principal's objective is to

\footnotetext{
${ }^{7}$ Kofman and Lawarrée (1993) were the first to explain collusion as an equilibrium phenomenon (see also Khalil and Lawarrée (1994) and Bac (1996)).
} 
maximize the net surplus associated with the public acquisition. The size of the market is fixed $Q \geq 0$. It generates a gross surplus $S(Q) \geq 0$ increasing with $Q\left(S^{\prime}(Q)>0\right)$. We assume that $S(Q)$ is large so that it is always worth procuring.

The firms: There are $N(\geq 1)$ potential firms in the economy. Depending on the commodity and on the economic circumstances, $N$ varies. The distribution of $N$ is common knowledge. ${ }^{8}$

A1

$$
N \in\{\underline{N}, \bar{N}\} \quad \text { with } \quad \alpha=\operatorname{Prob}(N=\bar{N}) .
$$

To serve the market the firms are confronted with a constant marginal cost function:

$$
C^{i}\left(\beta^{i}, q^{i}\right)=\beta^{i} q^{i} \quad \beta^{i} \in[\underline{\beta}, \bar{\beta}] \quad i=1, \ldots, N
$$

The term $q^{i} \geq 0$ is the output of firm $i$ in total production $\left(\sum_{i=1}^{N} q^{i}=Q\right)$, and $\beta^{i}$ is firm $i$ 's marginal cost. The market share $q^{i}$ is verifiable while $\beta^{i}$ is privately known. We assume that at the pre-contracting stage a firm does not know the exact value of $\beta^{i}$. This assumption reflects the fact that there are idiosyncratic shocks affecting the production process. From an ex-ante point of view, the $\beta^{i}$ are independently and identically distributed on $[\underline{\beta}, \bar{\beta}]$ according to the density function $f($.$) associated with the distribution$ function $F($.$) . The support [\underline{\beta}, \bar{\beta}]$, and the functions $F(),. f($.$) are common knowledge.$ To avoid bunching, we make the classical monotone hazard rate assumption:

A2

$$
F(\beta) / f(\beta) \text { is non decreasing for all } \beta \in[\underline{\beta}, \bar{\beta}] .
$$

The delegate: The delegate's job is to implement the acquisition procedure. She can either negotiate the market with a producer, in which case she needs to identify one, this corresponds to limited tendering as termed in the General Procurement Agreement

\footnotetext{
${ }^{8}$ We assume that it is binomial, but we could consider more general distribution.
} 
(GPA), or allocate it through competitive bidding procedure, this corresponds to open tender as termed in the GPA. The optimal decision depends on the relative cost to foster competition compared to the expected benefit. The cost of running open tender which is common knowledge, is fixed $K \geq 0$. It embodies the monetary and non monetary (delay) costs of the procedure. In practice these costs are very high. ${ }^{9}$ The benefit on the other hand is uncertain. It depends on how successful the bidding procedure is, that is, on $N$ the number of firms that submit an offer. The principal in the paper are the taxpayers. It is impossible for them to know in advance the number of potential bidders in the public markets to come. The principal simply knows that some markets are going to be competitive and that others are not going to be competitive. Since this information is crucial to choose the acquisition procedure, the delegate job is to gather information on the competitiveness of the market. ${ }^{10}$

The information acquisition process is exogeneous. The delegate holds information, denoted $\sigma$, on $N$. Following Laffont and Tirole (1993) we assume that with probability $\xi$ the delegate information is pertinent and with probability $1-\xi$ it is uninformative.

A3

$$
\sigma \in\{N, \emptyset\} \quad \text { with } \quad \xi=\operatorname{Prob}(\sigma=N) \text {. }
$$

The information received by the delegate is hard evidence. When she is informed that $\sigma=\underline{N}$ or that $\sigma=\bar{N}$, she can prove it in court. However she can always hide her

\footnotetext{
${ }^{9}$ It takes time and money to organize open tenders. First the purchasing entity has to specify its need in writing. Next it has to advertise tender information in official gazettes, newspapers, bulletin board or bidding information journals. If the firms that get the information are interested they have to work out detailed offers. The purchasing entity has to review and evaluate the offers. Finally it has to write a report to justify its choice. E-procurement reduces substantially these costs. For instance the State of California was able to save USD 9.7 million annually in procedural costs simply by switching from manual to online processing of purchase orders (see www.pd.dgs.ca.gov/calbuy/aboutcalby.htm).

${ }^{10}$ In the process she is also supposed to gather information on the identity of the potential bidders. Actually finding names is an important part of her job. For each purchase there is hence a name to single out in case of sole sourcing and a list of names to gather in case of competitive bidding.
} 
information and pretend that $\hat{\sigma}=\emptyset$. This claim is impossible -extremely costly- to verify. The principal needs to provide incentives to make the delegate reveal $\sigma$. The minimal bonus which ensures truthful revelation depends on a personal discount rate for illegal revenue, $\delta \in[0,+\infty)$. Term $\delta$ reflects the individual integrity "price": one unit of money received illegally is worth $\frac{1}{1+\delta} \leq 1$ to her. Finally the delegate needs to receive at least her reservation income, normalized without loss of generality to zero. This fixed wage ensures her participation but provides no guarantee concerning her loyalty at work.

\section{The timing:}

$t=1$ The principal sets the delegate's contract and the acquisition rules. He entrusts the enforcement of the acquisition rules to the delegate.

$t=2$ Nature chooses $N$; The delegate obtains information $\sigma$ about $N$, $t=3$ The delegate who gets all the bargaining power, meets with one firm; Side contracting occurs; ${ }^{11}$

$t=4$ The delegate announces $\hat{\sigma}$; she chooses competitive bidding or sole sourcing according to the rule edited by the principal.

- If it is competitive bidding, the delegate sinks $K$ and opens the market; Nature chooses $\left(\beta^{1}, \ldots, \beta^{N}\right)$; The $N$ potential producers discover $\beta^{i}$; bidding takes place.

- If it is sole sourcing, the delegate selects a firm; Nature chooses $\beta^{i}$; the firm discovers $\beta^{i}$; negotiation takes place.

$t=5$ Contracts are signed, production and transfer occur.

Step 3 corresponds to the corruption stage. We assume that the delegate gets all the bargaining power in the secret negotiation because if the firm refused her take-it-or-leave-

\footnotetext{
${ }^{11}$ At this stage of the game, both the firm and the delegate ignore the realization of $\beta$. The bribes are chosen based on the future expected profit of the firm.
} 
it offer she would make the same offer to a competitor. The bribe she gets is the maximum that a producer is willing to pay to secure a monopoly position. It is not important which one is chosen; Ex-ante, they are all symmetric. The next section provides the benchmark case of an incorruptible delegate (i.e., $\delta=+\infty)$.

\section{Benevolent Delegate: $\delta=+\infty$}

3.1 Sole Sourcing: In the sole source case the delegate duty is to find a producer to serve the market. ${ }^{12}$ Since she cannot observe the firm's marginal cost, the total acquisition cost is equal to $t(\beta)=\bar{\beta} Q .{ }^{13}$ The sole source case corresponds to a fixed price purchase. The identity of the producer then is irrelevant to the tax-payers. The principal's net expected surplus is constant, $W=S(Q)-\bar{\beta} Q$. On the other hand, the firm net profit, $\Pi(\beta)=(\bar{\beta}-\beta) Q$, decreases with $\beta$.

3.2 Competitive Bidding: When the delegate chooses a competitive procedure, since the firms' cost parameters are independently and identically distributed, it is optimal under asymmetry of information to organize a second price type of auction (see Myerson (1981)). ${ }^{14}$ The rent that a producer gets on expectation when he is one of $N$ bidders of such an auction is:

$$
E \Pi_{N}^{i}=Q \int_{\underline{\beta}}^{\bar{\beta}}[1-F(\beta)]^{N-1} F(\beta) d \beta \quad i=1, \ldots, N
$$

Compared with the sole source case, the expected rent in (2) is reduced by $[1-F(\beta)]^{N-1}$

\footnotetext{
${ }^{12}$ The way she identifies one is irrelevant for the analysis. We leave it a black-box.

${ }^{13}$ With a single producer we drop for notation simplicity the index of the firm.

${ }^{14}$ The firms submit independently a price above which they accept to serve the market. The market is attributed to the firm with the lowest bid, but the price it gets in exchange for the production is the second lowest bid. With such an auction it is a dominant strategy for each producer to announce its true marginal cost.
} 
which is the probability that a firm of type $\beta$ is not minimizing the acquisition cost. ${ }^{15}$

Let $f_{\min }^{N}(\beta)=N[1-F(\beta)]^{N-1} f(\beta)$ denote the density function of $\min \left(\beta^{1}, \ldots, \beta^{N}\right)$ the minimum of $N$ independent variable of type $\beta^{i}$, and $F_{m i n}^{N}(\beta)=1-[1-F(\beta)]^{N}$ the cumulative distribution function. We deduce from (2) that $\sum_{i=1}^{N} E \Pi_{N}^{i}=Q \int_{\underline{\beta}}^{\bar{\beta}} \frac{F(\beta)}{f(\beta)} d F_{\min }^{N}(\beta)$. The net expected surplus from competitive sourcing with $N$ bidders is:

$$
E W^{N}=S(Q)-Q \int_{\underline{\beta}}^{\bar{\beta}}\left(\beta+\frac{F(\beta)}{f(\beta)}\right) d F_{m i n}^{N}(\beta)-K
$$

A comparison of the welfare under sole sourcing with the welfare under competitive bidding omitting the fixed cost, yields after an integration by part $E W^{N}-W+K=$ $Q \int_{\underline{\beta}}^{\bar{\beta}}\left[1+\frac{d}{d \beta} \frac{F(\beta)}{f(\beta)}\right]\left(F_{m i n}^{N}(\beta)-F(\beta)\right) d \beta \geq 0 .{ }^{16}$ By introducing competition, the delegate reduces the producers' expected rent. Since these rents are a cost to the principal, competitive bidding increases his surplus by that much amount. The benefit grows as competition intensifies (the difference between $F_{m i n}^{N}($.$) and F($.$) increases with N$ ). Indeed, when the number of bidders is large they collectively bid more aggressively, which reduces the final cost. We define $k(N)$ as the marginal social benefit of introducing competition:

$$
k(N)=\int_{\underline{\beta}}^{\bar{\beta}}\left[1+\frac{d}{d \beta} \frac{F(\beta)}{f(\beta)}\right]\left[F_{m i n}^{N}(\beta)-F(\beta)\right] d \beta .
$$

The choice between sole sourcing and competitive bidding reduces to the following trade-off. Competitive bidding yields a procedural cost $K$ but gives a higher probability of a small acquisition cost, the sampling effect which is captured by $Q k(N) .{ }^{17}$ As $N$ is unknown ex ante, $k(N)$ is a random variable. The expected value of $k(N)$ depends on the information available on $N$. Let $\bar{k}=k(\bar{N}), \underline{k}=k(\underline{N})$, and $E k=\alpha \bar{k}+(1-\alpha) \underline{k}$. We

\footnotetext{
${ }^{15}$ In the sole source case $\Pi(\beta)=(\bar{\beta}-\beta) Q$ so that $E \Pi(\beta)=Q \int_{\underline{\beta}}^{\bar{\beta}} F(\beta) d \beta$.

${ }^{16}$ The expected surplus under sole sourcing is $W=S(Q)-\bar{\beta} Q=S(Q)-Q \int_{\underline{\beta}}^{\bar{\beta}}\left(\beta+\frac{F(\beta)}{f(\beta)}\right) d F(\beta)$.

${ }^{17}$ For more on the sampling effect see Auriol and Laffont (1993), Auriol (1996).
} 
deduce from (4) that $\underline{k} \leq E k \leq \bar{k}$. Conditionally on $\sigma$ we get $E[k(N) \mid N]=k(N)$ and $E[k(N) \mid \emptyset]=E k$.

Proposition 1 The optimal acquisition policy consists of choosing open tendering whenever $K$ is lower than $Q E[k(N) \mid \sigma]$ and limited tendering otherwise.

Competitive acquisition is more valuable when the number of bidders $N$ is large and when the level of procedural cost $K$ is low. Moreover, the expected gain associated with competitive bidding increases with $Q$. The impact of a decrease in the marginal acquisition cost is proportional to the market size. Efficiency, which is not a big issue for small markets (flexibility and rapidity are more important factors) is crucial for the large ones. In most countries in the world there are hence minimum thresholds for open tendering. We study next the optimal delegation scheme when the delegate is corruptible.

\section{Corruptible Delegate: $\delta<+\infty$}

By virtue of Proposition 1 when $Q \leq \frac{K}{\bar{k}}$ (i.e., the market is small) or when $Q \geq \frac{K}{k}$ (i.e., the market is big) the information possessed by the delegate on $N$ is socially useless. There is no stake for corruption. ${ }^{18}$ On the other hand, when $\frac{K}{\bar{k}} \leq Q \leq \frac{K}{E k}$, the optimal policy entails open tender if $\sigma=\bar{N}$, and limited tender otherwise. Since her information is pivotal, the delegate is free to choose the acquisition strategy whenever $\sigma=\bar{N}$. Then if a firm successfully captures the delegate, the principal ends up with the wrong decision, namely limited tendering in favor of the briber, whenever $\sigma=\bar{N}$. Finally, when $\frac{K}{E k} \leq Q \leq$ $\frac{K}{k}$, the optimal policy involves limited tendering if $\sigma=\underline{N}$, and open tendering otherwise.

\footnotetext{
${ }^{18}$ When $Q \leq \frac{K}{\bar{k}}$ The optimal acquisition policy is limited tendering independently of the signal $\sigma$ received by the delegate. Symmetrically, when $Q \geq \frac{K}{\underline{k}}$, the optimal policy is open tendering independently on $\sigma$.
} 
In the case $\sigma=\underline{N}$, the delegate can threaten a legitimate supplier of exclusion either by selecting a competitor, or worse for the taxpayers, by implementing open tendering (i.e., by claiming $\hat{\sigma}=\emptyset$ ) if it refuses to pay a bribe. This kind of corruption is called extortion: the firm does not want to bribe the delegate but is obliged to.

Figure 1 represents the possibilities of corruption in function of the market size $Q$. "Limited tender" and "open tender" are corruption-free zones. On the other hand corruption is called capture if the delegate decides to use limited tendering while she privately knows open tendering is optimal. It is called extortion if she asks a bribe from a firm while she privately knows limited tendering is optimal.

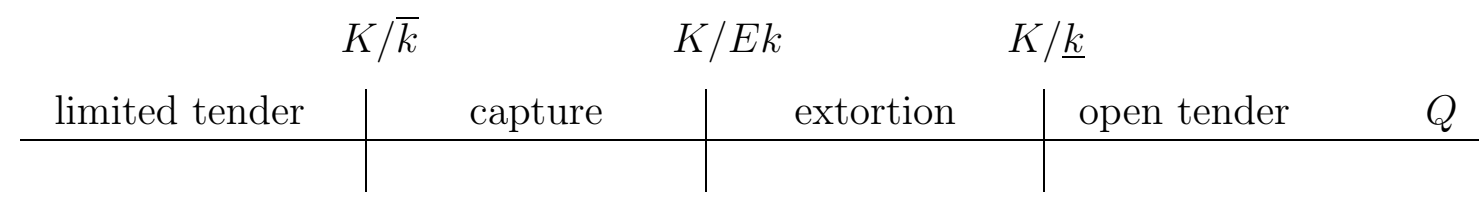

Figure 1

Extortion occurs when the optimal acquisition strategy is the fixed price purchase. To avoid being excluded from trade, a supplier abandons a share of its expected profit to the delegate. This alters the distribution of the rent between the delegate and the firm, but has no impact on the total acquisition cost. The taxpayers pay $\bar{\beta} Q$ anyway. In other words, extortion does not increase the final purchase cost. Since the burden of extortion lies entirely on the firms' shoulders, in the static context of the paper, fighting extortion generates costs and no benefit for taxpayers. The principal does not invest resources preventing the delegate from getting a kickback. Theoretically, it means that the collusion-proofness result does not hold when taking into account the possibility of extortion. ${ }^{19}$ Capture is different because it involves sole sourcing instead of competitive

\footnotetext{
${ }^{19}$ This does not imply that extortion is a social good. In practice people do not accept passively to be
} 
bidding when $\sigma=\bar{N}$ is pivotal information. The social loss associated with capture is

$$
L=Q k(\bar{N})
$$

with $k(N)$ defined equation (4). In comparison the firm's benefit from capture is: $\Delta \Pi=$ $E \Pi-E \Pi_{\bar{N}}^{i}$. It is an expected term because at the side-contracting stage the firms do not know the exact value of $\beta$. Then the stake for collusion is fixed and known to everybody which greatly simplifies the analysis of the corruption game. Let:

$$
\Delta \pi=\int_{\underline{\beta}}^{\bar{\beta}}\left[1-[1-F(\beta)]^{\bar{N}-1}\right] F(\beta) d \beta .
$$

One can check that $\Delta \Pi=Q \Delta \pi$. The next proposition establishes that capture creates a dead-weight loss. The proof is in Appendix 1.

Proposition 2 Contrary to extortion, capture increases the final purchase cost; The taxpayers' loss is higher than the firm's capture rent: $L \geq Q \Delta \pi$ for all $\bar{N} \geq 2$.

Capture involves allocative inefficiency on top of the bribes. ${ }^{20}$ It is not possible to assess the extra cost by classical survey techniques because nobody knows what would have been the final purchase cost if the most efficient supplier had won the tender. This information is out of equilibrium. To get a first approximation of the tax-payers' loss, one possibility consists in calibrating equation (5). In the absence of a better source of information the methodology provides a first estimate. Let $\Delta \beta=\bar{\beta}-\underline{\beta}$. We assume that A6 $\beta$ is uniformly distributed over $[\underline{\beta}, \underline{\beta}+\Delta \beta]$.

extorted. They try to bypass public agencies to avoid extortion. This shunting behavior might generate high efficiency costs. Moreover, in practice, susceptibility to corruption is endogeneous. Tolerating extortion might lead to an increase in corruption (i.e., a decrease in $\delta$ ). Then more extortion will also mean more capture. Studying these dynamic effects is beyond the scope of the paper.

${ }^{20}$ For instance, using electronic eavesdropping the US intelligence community maintained a top-secret database of international bribery cases. It lists hundreds of contracts worth hundreds of billions of dollars that went to the biggest briber rather than the highest bidder, over the past 18 years (NBC 2000). 
Assumption A6 implies equation (5) that $L=\Delta \beta Q \frac{N-1}{N+1} \cdot{ }^{21}$ Let $b$ denote the percentage of the total market cost which is paid in bribes: $B=b(\underline{\beta}+\Delta \beta) Q$. We obtain after some straightforward computations:

$$
L=\frac{\Delta \beta}{\underline{\beta}+\Delta \beta} \frac{N-1}{N+1} \frac{B}{b}
$$

The calibration exercise of (7) involves three terms. The first one represents in percentage the reduction of the purchasing price that would be realized if one could move from pure monopoly (i.e., from price $(\underline{\beta}+\Delta \beta) Q$ when $N=1)$ to perfectly competitive sourcing (i.e., to price $\underline{\beta} Q$ when $N=+\infty$ ). It is possible to assess a lower bound for $\frac{\Delta \beta}{\underline{\beta}+\Delta \beta}$ by looking at the impact of e-procurement on purchasing prices. ${ }^{22}$ Cases studies in the public sector reveal price reduction on the order of $20 \%{ }^{23}$ This figure is consistent with the $20 \%$ saving found by Domberger, Hall and Lee (1995) in their survey of the empirical literature on the impact of introducing competitive tendering in purchasing. A lower bound for $\frac{\Delta \beta}{\underline{\beta}+\Delta \beta}$ then is $0.2 .^{24}$ The second term in (7) depends on $N$ the number of bidders that would show up at a fair open tender. We rely on the US federal procure-

\footnotetext{
${ }^{21}$ The expected social loss associated with capture is increasing and concave in $N$ the number of bidders that would have competed in a fair open procedure. It varies between $L=\Delta \Pi$ when $N=2$ and $L=2 \Delta \Pi$ when $N \rightarrow+\infty$. This result is consistent with the empirical study by Iimi (2003) on procurement auctions for official development assistance. It shows that the bid prices decrease with the number of bidders in a convex fashion. Moving from open to limited tender hence yields a loss increasing and concave in $N$.

${ }^{22}$ E-procurement reduces substantially procurement procedural cost. The firms registered into the system receive automatically the tender offers. If they wish to submit an offer they do it electronically from their office. Since more firms are informed of the tender, and since it is less costly for them to submit an offer, the number of bidders increases. For instance, the number of bidders has been multiplied by 3 since the Korean administration completed its move from classical procurement to e-procurement (Park and Shin (2004)).

${ }^{23}$ For instance the introduction of e-procurement system in Brazil, COMPRASNET, and in Mexico, Compranet, brings an average $20 \%$ reduction of the final price for goods and services for both federal governments. See www.egov4dev.org/mexeproc.htm and www.egov4dev.org/brazeproc.htm (18/06/2004). Similarly since Romania introduced its e-GP system it saved some $22 \%$ on its purchases (IDA 2003).

${ }^{24}$ It represents a lower bound because in practice the purchases do not move from pure monopoly to perfect competition. For instance, the study by Kivisto and Virolainen (2005) on municipal public procurement activities in Finland focusing on a few selected basic products such as peeled potatoes or paper towels, reveals prices dispersion up to $180 \%$. The minimum prices dispersion in the sample is $10 \%$.
} 
ment data to calibrate this term. Appendix 3 shows that the average number of tenders weighted by their market value is $E N=7.139$. Setting $N=7$ yields $\frac{N-1}{N+1}=0.75$. On the other hand a lower bound for $N$ is 3 . It implies that $\frac{N-1}{N+1}=0.5 .^{25}$ We deduce that $\frac{N-1}{N+1} \in[0.5,0.75]$. Finally, a crucial parameter in calibrating the cost of capture is $b$. For a given amount of bribes $B$, if $b$ is small the annual volume of tainted procurement projects is large. That is, $\frac{B}{b}=T^{c}$ represents the worldwide public procurement spending which is affected by capture. Everything else being equal, it is better to have capture concentrated on a few markets with large bribes (i.e., with a large $b$ ), rather than to have it widespread with a smaller level of bribes. Indeed the capture dead-weight loss, $L-\Delta \Pi$, increases (linearly) with $T^{c}$. From a practical point of view, estimates of $b$ are available through survey techniques and police investigations. The examples listed in Appendix 3 suggest that a reasonable lower bound for $b$ is $5 \%$. On the other hand, the upper bound is $\frac{1}{12}$. We set $b \in\left[0.05, \frac{1}{12}\right]$. The taxpayers' loss then is $L \in[1.2,2.88] B$.

If the World Bank estimate, $B=200$, is accurate, in 2002 a lower bound for the worldwide loss of capture is USD 240 billion. An upper bound is USD 576 billion. The estimates represent between $4.14 \%$ and $9.93 \%$ of the world procurement spending. Even if these figures cannot be taken too literally, the magnitude of the dead-weight loss reveals a major economic problem. In what follows, we derive the optimal delegation framework to fight against it. We first consider the benchmark case where $\delta$ is observable to all.

\subsection{The Symmetric Information Case}

Under the assumption that $\delta \in[0,+\infty)$ is observable, any possible outcome can be obtained through a capture-proof contract (see Tirole 1986). There is, thus, no loss of

\footnotetext{
${ }^{25}$ See Appendix 3 for the computation, and see also footnote 22 for economic justification of $N \geq 3$.
} 
generality to restrict the analysis to situations where there is no bribe for capture in equilibrium. In equilibrium there is coexistence of the full revelation of delegate information and corruption (i.e. extortion). Let $x^{\sigma} \in[0,1]$ denote the probability that the principal chooses competitive bidding when the information disclosed by the delegate is $\sigma$ and $1-x^{\sigma}$ the probability that he chooses sole sourcing, $\sigma \in\{\underline{N}, \bar{N}, \emptyset\}$. The capture-proof rent is a bonus awarded to the delegate when $\sigma=\bar{N}$ is pivotal information. More precisely, the delegate behaves honestly if she receives from the principal the maximum amount she can get in bribes, by assumption $\Delta \Pi$, discounted by $1+\delta$.

As explained above $\sigma=\bar{N}$ is pivotal when $x^{\bar{N}}=1$ and $x^{\emptyset}=0$. The bonus is set to match the discounted capture rent, $B=\frac{Q \Delta \pi}{1+\delta}$. Then a capture-proofness contract for the delegate is:

$$
R(\sigma)= \begin{cases}x^{\bar{N}}\left(1-x^{\emptyset}\right) \frac{Q \Delta \pi}{1+\delta} & \text { if } \sigma=\bar{N} \\ 0 & \text { otherwise }\end{cases}
$$

Let

$$
\kappa=\frac{\alpha \xi}{\alpha \xi+1-\xi} \bar{k}+\frac{(1-\xi)}{\alpha \xi+1-\xi} E k
$$

be a convex combination of $\bar{k}$ and $E k$, and let

$$
\lambda(\delta)=1-\frac{1}{1+\delta} \frac{\Delta \pi}{\bar{k}} .
$$

Term $Q \bar{k} \lambda(\delta)$ represents the tax-payers' gain of implementing a capture-proof contract. The following result is proven in Appendix 1.

Proposition 3 When the corruptibility of the delegate $\delta$ is known, the optimal delegation framework distinguishes four regimes:

(i) $Q \lambda(\delta) \leq \frac{K}{\bar{k}} \quad \forall Q \leq \frac{K}{\kappa}$ : the acquisition procedure is limited tender. 
(ii) $Q \lambda(\delta) \geq \operatorname{Max}\left\{\frac{K}{\bar{k}}, \frac{Q[\alpha \xi \bar{k}+(1-\xi) E k]-(1-\xi) K}{\alpha \xi \bar{k}}\right\} \quad \forall Q \in\left[\frac{K}{\bar{k}}, \frac{K}{E k}\right]$ : the acquisition procedure depends on delegate information sustained by capture-proof contracts.

(iii) $Q \lambda(\delta) \leq \frac{Q[\alpha \xi \bar{k}+(1-\xi) E k]-(1-\xi) K}{\alpha \xi \bar{k}} \forall Q \in\left[\frac{K}{\kappa}, \frac{K}{\underline{k}}\right]$ : the acquisition procedure depends naively on delegate announcement so that extortion occurs.

(iv) $Q \geq \frac{K}{\underline{k}}$ : the acquisition procedure is open tender.

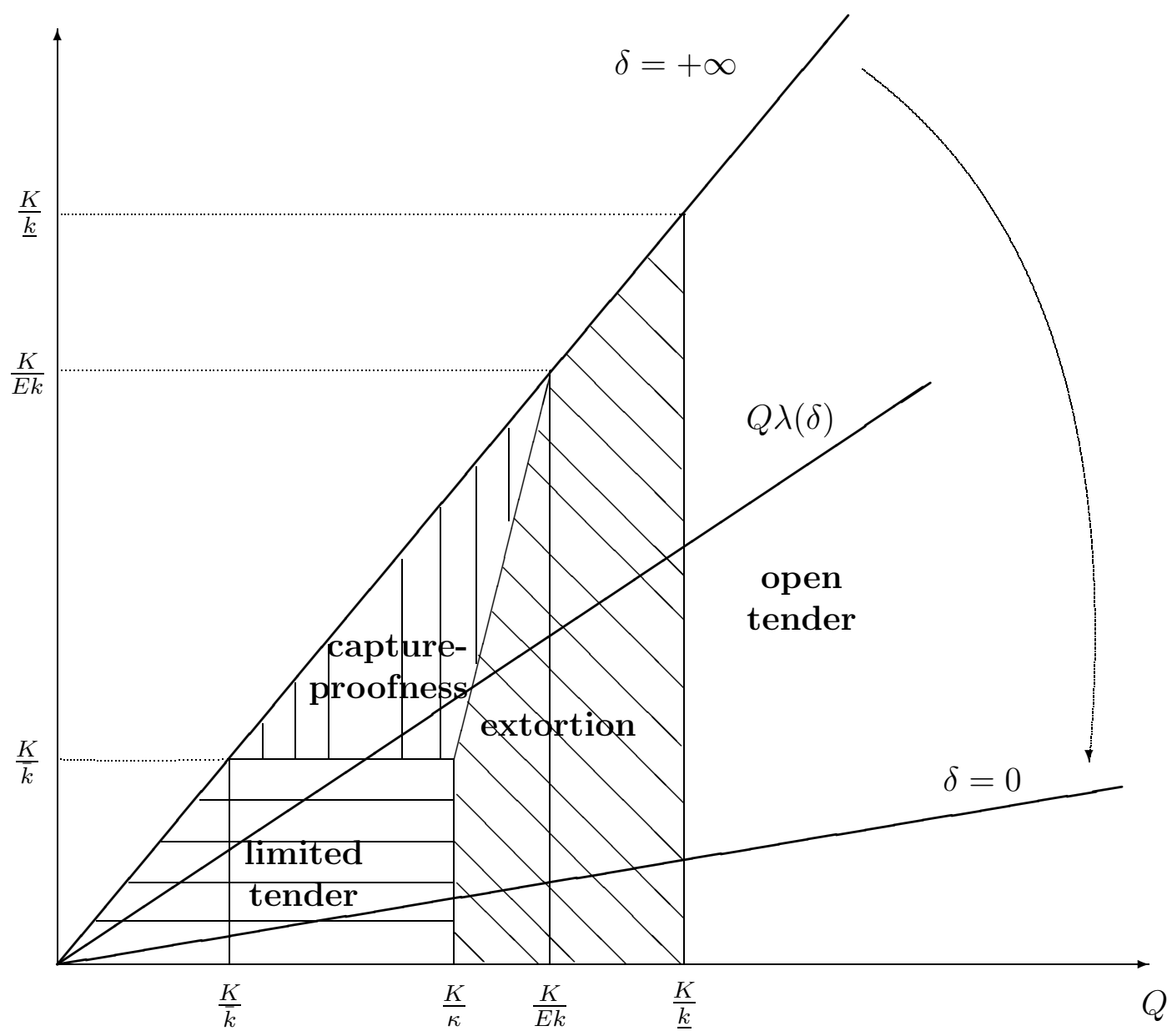

Figure 2: The Symmetric Information Case

Figure 2 illustrates Proposition 3. The line $Q \lambda(\delta)$ describes the regime to be implemented in function of $Q$.

Contrary to the first best case, the purchasing procedure depends both on the market 
value $Q$ and on the delegate susceptibility to corruption $\delta$. To get an intuition of how conditions $(i)$ to $(i v)$ are derived, consider first the limit case where the delegate is not corruptible (i.e., $\lambda(+\infty)=1$ ). It is easy to check that Proposition 1 and 3 coincide. Similarly when $\delta$ is finite the optimal rule is first best for $Q \in\left[0, \frac{K}{\bar{k}}\right] \cup\left[\frac{K}{E k},+\infty\right)$. As illustrated by Figure 2 the distortion of the rule appears only for $Q \in\left[\frac{K}{\bar{k}} \frac{K}{E k}\right]$. Indeed, to deter the capture threat, the principal needs to offer incentive contracts to the delegate. The bonus increases the purchase cost. The principal compares the expected benefit of implementing the optimal acquisition decision with the capture-proof rent. He relies on the delegate expertise only if $Q \lambda(\delta) \geq \frac{K}{\bar{k}}$. From (9), $\lambda(\delta)$ which is lower than 1 , is increasing in $\delta$. The interval in term of market size, where the principal implements capture-proof contracts, shrinks when $\delta$ decreases. ${ }^{26}$ For very corrupted agents the capture regime may be totally suppressed. That is, for the low value of $\delta, Q \lambda(\delta) \leq \frac{K}{\bar{k}} \forall Q \in\left[\frac{K}{\bar{k}}, \frac{K}{E k}\right]$, may occur. The delegate receives a flat wage -her reservation wage- and the principal is confronted with the following choice. He can either neglect's the delegate information -limited tender- or partly use it -extortion regime. It is easy to check that extortion dominates limited tendering when $Q \in\left[\frac{K}{\kappa}, \frac{K}{E k}\right]$, and that the reverse is true when $Q \in$ $\left[\frac{K}{\bar{k}}, \frac{K}{\kappa}\right]$. In this case, the delegate retains choice only for $Q \in\left[\frac{K}{\kappa}, \frac{K}{\underline{k}}\right]$, as compared to $Q \in\left[\frac{K}{\bar{k}}, \frac{K}{\underline{k}}\right]$ in the first best. In response to the capture threat, the principal reduces the delegate's discretion. This is the lack of discretion result stressed by the collusionproofness literature.

\footnotetext{
${ }^{26}$ Proposition 3 establishes that for a given $Q \in\left[\frac{K}{\bar{k}}, \frac{K}{E k}\right]$, the capture-proof regime is implemented only if $Q \lambda\left(\delta_{c}\right) \geq \operatorname{Max}\left\{\frac{K}{\bar{k}}, \frac{Q[\alpha \xi \bar{k}+(1-\xi) E k]-(1-\xi) K}{\alpha \xi \bar{k}}\right\}$. From (9) $\lambda(\delta)$ increases with $\delta$; $\operatorname{Max}\left\{\frac{K}{\bar{k}}, \frac{Q[\alpha \xi \bar{k}+(1-\xi) E k]-(1-\xi) K}{\alpha \xi \bar{k}}\right\}$ is independent of $\delta$. We deduce the result.
} 


\subsection{The Asymmetric Information Case}

As first pointed out by Kofman and Lawarrée (1996) and by Strausz (1998), it is not realistic to assume that the principal knows the corruptibility of his delegates. If he was able to identify corruptibility, he would hire honest delegates only. The principal does not know $\delta$, but has a prior on this parameter given by the distribution function $G(\delta)$ and the density function $g(\delta)$ over $[0,+\infty)$ satisfying the monotone hazard rate property.

A4 $\frac{1-G(\delta)}{g(\delta)}$ is decreasing $\forall \delta \in[0,+\infty)$.

To capture the idea that corruption varies across place and time, a population identified by its distribution function $G_{\theta}($.$) over [0,+\infty)$ is said to be more corrupted than a population identified by the distribution function $G_{\theta^{\prime}}($.$) if the following condition holds.$

A5

$$
\frac{1-G_{\theta}(\delta)}{g_{\theta}(\delta)} \leq \frac{1-G_{\theta^{\prime}}(\delta)}{g_{\theta^{\prime}}(\delta)} \quad \forall \delta \in[0,+\infty)
$$

Assumption 5 implies that a population which is corrupted is associated with lower bribes' discount rate than a more honest one.

If the principal cannot observe the delegates' type, he is not able to tailor the contracts in function of $\delta$. To be sure that the most corrupted delegate (i.e. $\delta=0$ ) will cooperate honestly, he has to abandon $Q \Delta \pi$ to all. He prefers to offer less, accepting in exchange the risk of having some capture in equilibrium. The principal chooses a critical value $\delta^{l}$ to optimize on the bonus $\frac{Q \Delta \pi}{1+\delta^{l}}$ that he offers to the delegate in exchange for the pivotal information $\sigma=\bar{N}$. If the delegate he faces is relatively honest (is of type $\delta \geq \delta^{l}$ ), she accepts the bonus and reports truthfully, which yields a net surplus $E W^{\bar{N}}-\frac{Q \Delta \pi}{1+\delta^{l}}$. If she is corrupted (is of type $\delta \leq \delta^{l}$ ), she prefers to hide her information and to collude with a producer, which yields the net surplus $E W$. The principal chooses $\delta^{l}$ to solve 
$\operatorname{Max}_{\delta}[1-G(\delta)]\left(E W^{\bar{N}}-\frac{Q \Delta \pi}{1+\delta}\right)+G(\delta) E W$ (see Appendix 1). We deduce that $\delta^{l}$ satisfies the following equation: ${ }^{27}$

$$
\frac{1-G\left(\delta^{l}\right)}{g\left(\delta^{l}\right)} \frac{1}{\left(1+\delta^{l}\right)^{2}}+\frac{1}{1+\delta^{l}}=\frac{Q \bar{k}-K}{Q \Delta \pi} .
$$

The marginal benefit associated with the decrease of the rent distributed to the honest fraction of the population, $\left[1-G\left(\delta^{l}\right)\right] \frac{Q \Delta \pi}{\left(1+\delta^{l}\right)^{2}}$, is equalized to the marginal cost of the increase in the number of captured delegates implementing distorted acquisition decisions, $g\left(\delta^{l}\right)\left[Q \bar{k}-\frac{Q \Delta \pi}{1+\delta^{l}}-K\right]$. From equation (10), one can check that $\delta^{l}$ decreases with $Q$. Indeed, for the large value of $Q$, an anti-competitive bias in the attribution process generates substantial cost overruns. To limit such a bias, the principal strengthens the delegate's incentives by increasing her unitary reward. Since $\delta^{l}$ decreases, the probability that the delegate is captured, $G\left(\delta^{l}\right)$, thus decreases with market size $Q$. Moreover, one can check that the optimal delegate's reward decreases when the level of corruption decreases among the population ( $\delta^{l}$ increases when delegate distribution shifts in A5 sense). If honesty rises among the population, more delegates are going to take the principal's bonus rather than bribes. It becomes very costly to offer $\frac{Q \Delta \pi}{1+\delta^{l}}$ to all of them, so the principal lowers the bonus. Theoretically, the collusion-proofness result does not hold when $\delta$ is not observable. Achieving zero corruption level is not a sensible objective for a government. The next proposition shows how the optimal delegation policy is distorted by the asymmetric information on $\delta$. The proof is similar to that of Proposition 3 in Appendix 1.

Proposition 4 When $\delta$ is not observable, the optimal delegation framework distinguishes four regimes to be implemented by the delegate in function of market size $Q$ :

\footnotetext{
${ }^{27}$ To avoid a corner solution we assume that $Q \bar{k}-Q \Delta \pi-K<0$ and that $G($.$) is non degenerate.$
} 
(i) $Q \leq \frac{K}{\bar{k}}$ : the acquisition procedure is limited tender.

(ii) $Q \lambda\left(\delta^{l}\right)-\frac{K}{\bar{k}} \geq \frac{\alpha \xi+1-\xi}{\alpha \xi} \frac{\kappa Q-K}{\bar{k}} \quad \forall Q \in\left[\frac{K}{\bar{k}}, \frac{K}{E k}\right]$ : the acquisition procedure depends on delegate announcement sustained by the incentive payment $\frac{Q \Delta \pi}{1+\delta^{l}}$ so that capture occurs with probability $\left.G\left(\delta^{l}\right)\right)$.

(iii) $Q \lambda\left(\delta^{l}\right)-\frac{K}{\bar{k}} \leq \frac{\alpha \xi+1-\xi}{\alpha \xi} \frac{\kappa Q-K}{\bar{k}} \quad \forall Q \in\left[\frac{K}{\kappa}, \frac{K}{\underline{k}}\right]$ : the acquisition procedure depends on the delegate's information so that extortion occurs.

(iv) $Q \geq \frac{K}{\underline{k}}$ : the acquisition procedure is open tender.

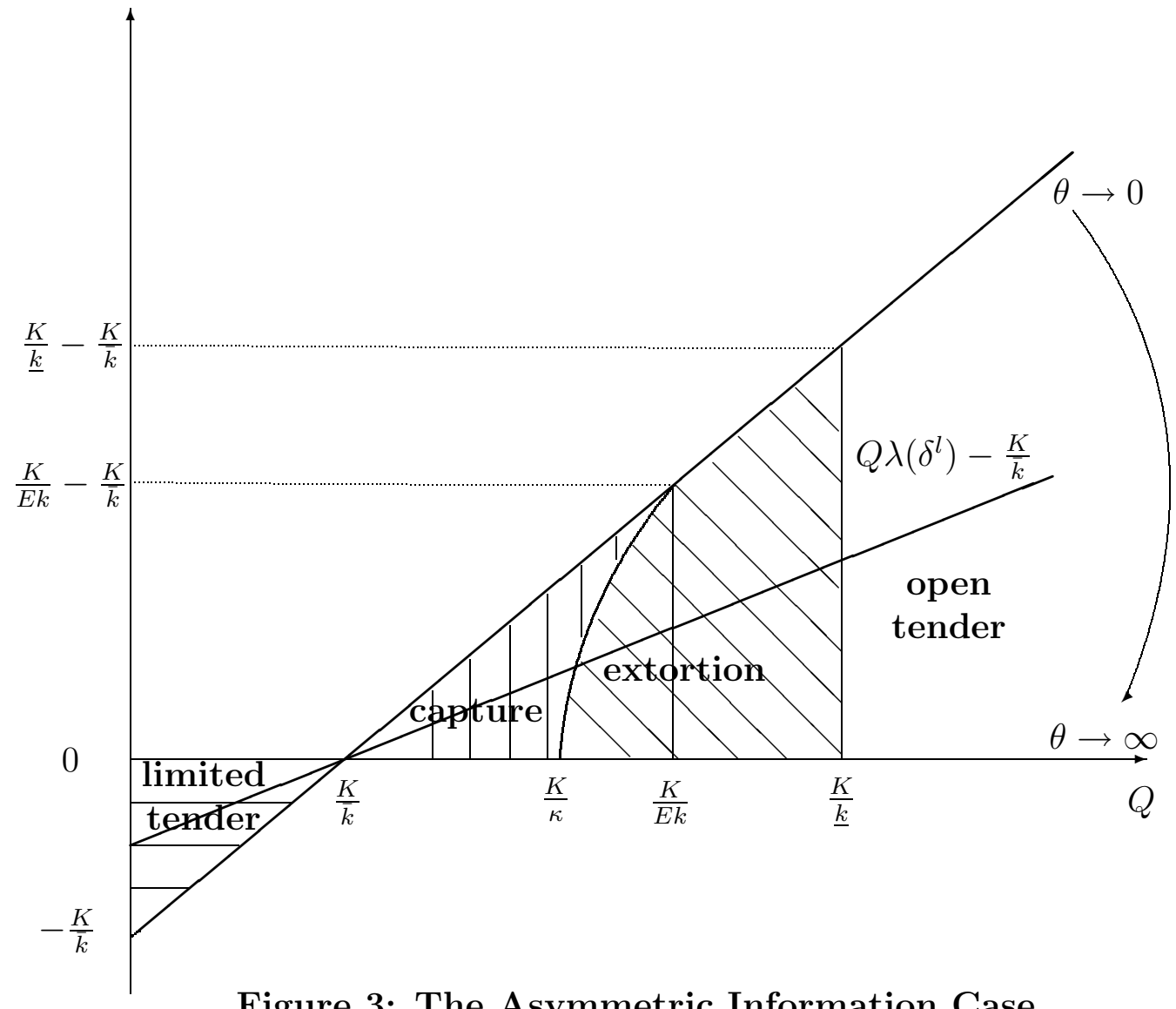

Figure 3: The Asymmetric Information Case

Figure 3 illustrates Proposition 4. It is drawn for the distribution function $G_{\theta}(\delta)=$ $1-\left[\frac{1}{1+\delta}\right]^{\theta} \quad \delta \in[0,+\infty], \quad \theta>0 .{ }^{28}$ For a given $Q$, the line $Q \lambda\left(\delta^{l}\right)-\frac{K}{\bar{k}}=\frac{1}{1+\theta}\left(Q-\frac{K}{\bar{k}}\right)$

\footnotetext{
${ }^{28} \mathrm{It}$ is parameterized by $\theta$ such that the greater $\theta$ is, the more the population is corrupted. The fraction
} 
provides the regime to be implemented.

The first result from Proposition 4 is that whatever the principal's belief in the corruptibility of the society, the rules concerning limited and open tender are first best. Limited tender is implemented when $\bar{k} Q \leq K$, open tender when $\underline{k} Q \geq K$ (see $(i)$ and $(i v)$ ). The rule is independent of the distribution function $G(\delta)$. This suggests that large public purchases should be ruled by international legislation. For instance, European legislation requires from EU members to publish procurement contracts in the Official Journal of the European Communities once they reach the values mentioned in the Government Procurement Agreement (GPA). Companies from countries that signed the GPA, including the USA, Canada, Israel and Japan, can participate on equal terms as companies from member-states of the EU. Promoting the adoption by other countries of such a unified procurement code is crucial to fight corruption in large purchases. On the other hand, governments have to be pragmatic. For small purchases the cost of running a competitive bidding procedure is prohibitive. In most countries in the world there is hence a minimum size below which the purchases are authorized directly by government officials. This rule is consistent with the result in Proposition 4.

The second result from Proposition 4 is that, whatever the distribution of corruptibility in the population, when $Q \in\left[\frac{K}{\bar{k}}, \frac{K}{\underline{k}}\right]$ the optimal policy is either to implement the capture or the extortion regime. Contrary to the symmetric information case, there is no loss of discretion in response to the corruption threat. However, there is a change in the discretion rule. The choice between the capture and the extortion regime depends, for a of the population which is honest is $\left[\frac{1}{1+\delta^{l}}\right]^{\theta}$. When $\theta \rightarrow 0$ the whole population is honest, and when $\theta \rightarrow+\infty$ it is totally corrupted. 
given distribution $G($.$) on Q$. Since the transfer $\frac{Q \Delta \pi}{1+\delta^{l}}$ increases more than proportionally when market size increases (because $\delta^{l}$ decreases when $Q$ increases), it becomes very costly to implement the capture regime for the large value of $Q$. The principal chooses rather a competitive procedure whenever the delegate claims that $\sigma=\emptyset$, which implies that extortion occurs.

Static comparative analysis shows that when the susceptibility to corruption in the population rises (in A5 sense), the delegate's decisions that might lead to capture are reduced. ${ }^{29}$ However, contrary to the symmetric information case, it is never totally suppressed. When corruption runs very high the capture regime is limited to the interval $Q \in\left[\frac{K}{\bar{k}}, \frac{K}{\kappa}\right]$. Indeed, for this range of the parameters, suppressing the discretion of the delegate would mean ignoring her information by always choosing limited tender, which is the decision that a corrupted delegate (i.e., $\delta \leq \delta^{l}$ ) is going to implement anyway (a corrupted delegate announces $\hat{\sigma}=\emptyset$ when $\sigma=\bar{N}$ ). On the other hand, a relatively honest delegate (i.e., $\delta \geq \delta^{l}$ ) is going to implement the principal's preferred decision in exchange for the bonus. For $Q \in\left[\frac{K}{\bar{k}}, \frac{K}{\kappa}\right]$, bypassing delegate information means the loss of this occasional increase in surplus without providing any corresponding benefit. ${ }^{30}$ Concretely this implies that in countries plagued by corruption extortion runs high. Legislation should hence make a distinction between facilitation payments and payments made to bypass competition. The former is a business cost, the latter is a crime against the taxpayers. The theoretical analysis also suggests that to fight capture the purchasers should

\footnotetext{
${ }^{29}$ The critical value $\delta^{l}$ decreases with corruption (in A5 sense), so that $Q \lambda\left(\delta^{l}\right)-\frac{K}{\bar{k}}$ also decreases with corruption. Since $\frac{\alpha \xi+1-\xi}{\alpha \xi} \frac{\kappa Q-K}{\bar{k}}$ is constant we deduce from proposition 4 that the capture regime is less implemented when corruption increases.

${ }^{30}$ Formally, we see from equation (10) that $Q \lambda\left(\delta^{l}\right)-\frac{K}{\bar{k}}=\frac{1}{\bar{k}} \frac{1-G\left(\delta^{l}\right)}{g\left(\delta^{l}\right)\left(1+\delta^{l}\right)} \geq 0 \forall Q \in\left[\frac{K}{\bar{k}}, \frac{K}{E k}\right]$. Moreover $\frac{\alpha \xi+1-\xi}{\alpha \xi} \frac{\kappa Q-K}{\bar{k}} \leq 0 \forall Q \in\left[\frac{K}{\bar{k}}, \frac{K}{\kappa}\right]$. Proposition 4 implies that the capture regime is always implemented.
} 
be awarded a bonus increasing with the market value. Britain pioneered such an incentive system. The top government officials receive a portion of the end of the fiscal year difference between their budget allowances and what they actually spent (Vaknin 2004). ${ }^{31}$

\section{Conclusion}

Facilitation payments are generally not covered by anti-bribery conventions. In contrast bribes for capture are against most national and international laws. There is a sound rationale for that: capture yields a dead-weight loss while extortion does not. Based on the model calibration, the loss from capture represents between $4.14 \%$ and $9.93 \%$ of the world procurement spending. Such level of government inefficiency calls for structural reform. Reforming public purchases is politically easier than, for instance privatizing and deregulating public utilities. Yet, international comparisons illuminate large gaps in governments' commitment to fight capture. For instance, under the GPA, limited tendering procedure is permissible only under very restrictive conditions. Nevertheless, its use varies widely across signatories from a reported zero level in Singapore and in Finland to more than 30 percent on average in France, Hong Kong, and Austria (see Hoekman 1998). Similarly, many former European colonies and most European countries such as France, have immunity laws to protect politicians in corruption cases (Barreto and Kessler 2004). They do not maintain a list of debarred suppliers: Firms that have been found guilty of active corruption are allowed to bid for new public contracts. The implementation of e-procurement is slow. Finally, the purchasers are not monitored and they receive the same reward no matter what size of the market they are dealing with.

\footnotetext{
${ }^{31}$ Similarly Alkadry (2004) found a statistical significant positive effect of the annual procurement volume on compensation of 448 heads of public procurement units and 414 supervisors and materials managers in the US public sector.
} 
It is hard to believe that such an inefficient public procurement framework has been designed while bearing cost minimization in mind. There is much documented evidence that political parties finance their campaigns, and their leaders' private accounts, with the money from capture. For instance in 2003, business leaders regarded illegal donations to political parties as common or fairly common in 41 percent of the 102 surveyed countries by the World Economic Forum. Among them we find mainly democracies. In contrast, in only 18 percent of the countries, including authoritarian regimes such as China, do business leaders claim that they are rare or fairly rare. Even though political competition is vital for democracy, the question of how it should be financed is not settled. The paper highlights that financing it with the money from capture is socially inefficient. 


\section{APPENDIX 1: Proof of Proposition 2}

Let $F_{m i n}^{N}(\beta)=1-(1-F(\beta))^{N}$ be the cumulative distribution of $\min \left(\beta^{1}, \ldots, \beta^{N}\right)$. One can check that $k(\bar{N})=\int_{\underline{\beta}}^{\bar{\beta}}\left[1+\frac{d}{d \beta}\left(\frac{F(\beta)}{f(\beta)}\right)\right] F_{m i n}^{\bar{N}-1}(\beta)(1-F(\beta)) d \beta$, and that $\Delta \pi=\int_{\underline{\beta}}^{\bar{\beta}} F_{m i n}^{\bar{N}-1}(\beta) F(\beta) d \beta$. It yields after some integration by part: $k(\bar{N})-\Delta \pi=\int_{\underline{\beta}}^{\bar{\beta}}(1-F(\beta))\left\{\frac{F_{\min }^{\bar{N}-1}(\beta)}{f_{\min }^{\bar{N}-1}(\beta)}-\frac{F(\beta)}{f(\beta)}\right\} d F_{\min }^{\bar{N}-1}(\beta)$. Let $S(\beta)=1-F(\beta)$. We get: $\frac{F_{\min }^{\bar{N}-1}(\beta)}{f_{\min }^{\bar{N}-1}(\beta)} \geq \frac{F(\beta)}{f(\beta)} \Leftrightarrow 1-S(\beta)^{\bar{N}-1} \geq(\bar{N}-1)[1-S(\beta)] S(\beta)^{\bar{N}-2}$ which is true for all $\bar{N} \geq 2$ since $S(\beta) \in[0,1]$. We deduce that $k(\bar{N})-\Delta \pi \geq 0$ for $\bar{N} \geq 2$.

\section{APPENDIX 2: Proof of Proposition 3 and 4}

Proposition 3: Taking into account the capture-proofness rent that he must abandon to the delegate (i.e., $\frac{Q \Delta \pi}{1+\delta}$ when $\sigma=\bar{N}$ is pivotal information) and the informational rent that he must abandon to the firms ${ }^{32}$ the principal's expected welfare function is: ${ }^{33}$

$$
\begin{aligned}
E V= & (1-\xi)\left\{\left(1-x^{\emptyset}\right) W+x^{\emptyset}\left(\alpha E W^{\bar{N}}+(1-\alpha) E W^{\underline{N}}\right)\right\}+\xi(1-\alpha)\left\{\left(1-x^{\underline{N}}\right) W+x^{\underline{N}} E W^{\underline{N}}\right\} \\
& +\xi \alpha\left\{\left(1-x^{\bar{N}}\right) W+x^{\bar{N}} E W^{\bar{N}}-x^{\bar{N}}\left(1-x^{\emptyset}\right) \frac{Q \Delta \pi}{1+\delta}\right\} .
\end{aligned}
$$

The principal's objective is to maximize with respect to $x^{\sigma} \in[0,1]$ the function $E V$.

Since $E V$ is linear in $x^{\sigma}$ at the optimum the probabilities are either 0 or $1: x^{\sigma} \in\{0,1\}$.

Recall that $E W^{N}-W=k(N) Q-K$ with $k(N)$ defined equation (4). We get that

$$
\begin{aligned}
E V= & (1-\xi)\left\{W+x^{\emptyset}(Q E k-K)\right\}+\xi(1-\alpha)\left\{W+x^{\underline{N}}(Q \underline{k}-K)\right\} \\
& +\xi \alpha\left\{W+x^{\bar{N}}\left(Q \bar{k}-K-\left(1-x^{\emptyset}\right) \frac{Q \Delta \pi}{1+\delta}\right)\right\} .
\end{aligned}
$$

Optimizing $E V$ with respect to $x^{\sigma} \in\{0,1\}$ it is easy to check that:

- If $Q \bar{k}-K<0$ then $x^{\underline{N}}=x^{\bar{N}}=x^{\emptyset}=0$ (i.e., limited tender);

\footnotetext{
${ }^{32}$ The rent has the same shape as in section 3 because the information structure between the delegate and the firms regarding $\beta^{i}$ is unchanged.

${ }^{33}$ To understand how the principal objective function is built, consider the case when the delegate learns nothing, $\sigma=\emptyset$. The associated expected welfare is $V^{\emptyset}=\left(1-x^{\emptyset}\right) W+x^{\emptyset}\left(\alpha E W^{\bar{N}}+(1-\alpha) E W \underline{N}\right)$, which corresponds to the first parenthesis. It occurs with probability $(1-\xi)$. The second parenthesis corresponds to the case where the delegate learns that $\sigma=\underline{N}$, and the third parenthesis to the case where $\sigma=\bar{N}$. These events occur with the probability $\xi(1-\alpha)$ and $\xi \alpha$ respectively.
} 
- If $Q \underline{k}-K>0$ then $x^{\underline{N}}=x^{\bar{N}}=x^{\emptyset}=1$ (i.e., open tender);

- If $Q \underline{k}-K<0<Q E k-K$ then $x^{\underline{N}}=0$ and $x^{\bar{N}}=x^{\emptyset}=1$ (i.e., extortion regime).

We deduce that for $Q \in\left[0, \frac{K}{\bar{k}}\right] \cup\left[\frac{K}{E k},+\infty\right)$ the optimal rule is as described Proposition 1 .

The new part of the analysis arises for $Q \in\left[\frac{K}{\bar{k}}, \frac{K}{E k}\right]$. In this case $Q \underline{k}-K<0$ so that $x^{\underline{N}}=0$. The principal maximizes with respect to $x^{\emptyset}, x^{\bar{N}} \in\{0,1\}$ :

$E V=W+(1-\xi) x^{\emptyset}(Q E k-K)+\alpha \xi x^{\bar{N}}\left[\left(1-x^{\emptyset}\right)(Q \lambda(\delta) \bar{k}-K)+x^{\emptyset}(Q \bar{k}-K)\right]$.

Since $x^{\underline{N}}=0$, several cases occur:

- If $Q \lambda(\delta) \leq \frac{K}{\bar{k}}$ and $Q \kappa \leq K$ then $x^{\bar{N}}=x^{\emptyset}=0$ (i.e., limited tender). ${ }^{34}$

- If $Q \lambda(\delta) \geq \frac{K}{\bar{k}}$ and $Q \kappa \leq K$, then $x^{\bar{N}}=1$ and $x^{\emptyset}=0$ (i.e., capture-proofness).

- If $Q \lambda(\delta) \leq \frac{K}{\bar{k}}$ and $Q \kappa \geq K$ then $x^{\bar{N}}=x^{\emptyset}=1$ (i.e., extortion).

- If $Q \lambda(\delta) \geq \frac{K}{\bar{k}}$ and $Q \kappa \geq K$ then $x^{\bar{N}}=1$. For $x^{\emptyset}$ two cases are possible:

- If $\frac{(\alpha \xi+1-\xi) Q \kappa-(1-\xi) K}{\alpha \xi \bar{k}} \leq Q \lambda(\delta)$ then $x^{\emptyset}=0$ (i.e., capture-proofness),

- If $\frac{(\alpha \xi+1-\xi) Q \kappa-(1-\xi) K}{\alpha \xi \bar{k}}>Q \lambda(\delta)$ then $x^{\emptyset}=1$ (i.e., extortion).

Aggregating the results yields Proposition 3.

Proposition 4: We maximize with respect to $x^{\hat{\sigma}} \in[0,1]$ :

$E V^{A I}=(1-\xi)\left\{\left(1-x^{\emptyset}\right) W+x^{\emptyset}\left(\alpha E W^{\bar{N}}+(1-\alpha) E W^{\underline{N}}\right)\right\}+\xi(1-\alpha)\left\{\left(1-x^{\underline{N}}\right) W+x^{\underline{N}} E W^{\underline{N}}\right\}$ $+\xi \alpha\left\{\left(1-x^{\bar{N}}\right) W+x^{\bar{N}} x^{\emptyset} E W^{\bar{N}}+x^{\bar{N}}\left(1-x^{\emptyset}\right)\left(\left(1-G\left(\delta^{l}\right)\right)\left(E W^{\bar{N}}-\frac{Q \Delta \pi}{1+\delta^{l}}\right)+G\left(\delta^{l}\right) E W\right)\right\}$ with $W=S(Q)-\bar{\beta}, E W^{N}$ defined equation (3), $Q \Delta \pi$ equation (6), $\delta^{l}$ equation (10). The proof of Proposition 4 is similar to that of Proposition 3.

\section{APPENDIX 3: Calibration of $L=\frac{\Delta \beta}{\beta+\Delta \beta} \frac{N-1}{N+1} \frac{B}{b}$}

- Data on e-procurement and on competitive bidding suggest that $\frac{\Delta \beta}{\underline{\beta}+\Delta \beta} \geq 0.2$

\footnotetext{
${ }^{34}$ Indeed if $Q \lambda(\delta) \bar{k}-K \leq 0$ then $\alpha \xi x^{\bar{N}}\left(1-x^{\emptyset}\right)=0$ and if $\alpha \xi(Q \bar{k}-K)+(1-\xi)(Q E k-K) \leq 0$ then $x^{\emptyset}=0$.
} 
- For the number of bidders I rely on the US Federal Procurement Data. The following summary table of US federal procurement data has been kindly provided by Paul Murphy from Eagle Eye Publishers Inc. I am very grateful for his help.

\begin{tabular}{|c|c|c|c|}
\hline Number of Offers & Amount $\mathbf{\$ 0 0 0 )}$ & \% of Total & Actions \\
\hline 1 & $\$ 109,634,111$ & $40.68 \%$ & 217,973 \\
$2-5$ & $\$ 100,658,576$ & $37.35 \%$ & 329,00 \\
$6-10$ & $\$ 22,007,186$ & $8.17 \%$ & 67,016 \\
$11-15$ & $\$ 6,209,296$ & $2.30 \%$ & 27,063 \\
$16-20$ & $\$ 3,998,960$ & $1.48 \%$ & 11,930 \\
$21-50$ & $\$ 7,265,024$ & $2.70 \%$ & 26,983 \\
OVER 50 & $\$ 19,755,081$ & $7,33 \%$ & 108,188 \\
\hline
\end{tabular}

Source: Eagle Eye Publishers Inc., Fairfax, Virginia - November 09, 2004.

The first column lists the number of offers received by the Federal authority. The second column lists the value of the markets in thousands of US dollars. The third column expresses these amounts as a percentage of the total federal markets' value. The last column lists the number of contracts in each category. In US federal procurement $40.68 \%$ of the markets (in value) is attributed through direct negotiation with a single producer. This corresponds to the "limited tender" cases in this paper. It covers many defense contracts. The other procedures, representing $59.3 \%$ of procurement value, involve 2 offers or more. They are denoted "open tender" in the paper. To compute the average number of tender I add the average number of offers in each category (assuming a uniform distribution) weighted by its market share in value (i.e., $\%$ of the total). For instance the weight of group $[2,5]$ is $\frac{5+2}{2} 0.373=1.31$. We deduce that $E N=\frac{2+5}{2} 0.373+\frac{6+10}{2} 0.082+\frac{11+15}{2} 0.023+$ $\frac{16+20}{2} 0.015+\frac{21+50}{2} 0.027+(50) 0.073=7.139$. To fix a lower bound for $N$, I focus on the average number of tenders for federal procedures involving less than 50 offers. $^{35}$

\footnotetext{
${ }^{35}$ Public purchases with more than 50 tenders are typically standardized commodities. They are less likely to involve capture.
} 
Subtracting from $E N=7.139$ the value (50)0.073 yields $E N \geq 7.139-3.65=3.489$.

- Estimates of $b$ are available through survey techniques and police investigations. For instance the average amount paid in bribes as a percentage of the total cost of doing business would be $5 \%$ in Asia (The Economist 1995). This figure is consistent with the opinion of Zhu Shaoping, a legal expert about Chinese public purchases: "Commonly, an average of 5 percent of the country's total governmental investments ends up in private purses in the form of kickbacks" (Shangai Star 2001). Similarly, TI in Nepal conducted a study at the municipal level to evaluate the impact of the adoption of an integrity pact. TI found that, before the implementation of the integrity pact, the level of bribes were between $5 \%$ and 6\% ${ }^{36}$ In Pakistan, a kickback commission at the rate of $6 \%$ of the total contract was agreed upon with French companies, including Aerospatiale and Thompson CSF, for naval defense contracts (Farooq 2001). In France, the bribes paid by firms in construction markets in the area of Paris were found to be between $5 \%$ and 10\% (Le Monde 1996). A reasonable lower bound for $b$ then is $5 \%$. It is worth noting that the $5 \%$ bound is consistent with the World Bank estimates which put bribes paid to win public market in the vicinity of $3.5 \%$ of total procurement cost. Since capture does not occur in all public purchases, when it occurs, on average, the bribe cut is higher. Finally, an upper bound for $b$ is derived from the theoretical analysis. By assumption $B \leq \Delta \Pi$ which is equivalent to $b \leq \frac{\Delta \beta}{\underline{\beta}+\Delta \beta} \frac{N(N+1)-2}{2 N(N+1)}$. With $\frac{\Delta \beta}{\underline{\beta}+\Delta \beta}=0.2$ and $N=3$ we get that $\frac{\Delta \beta}{\underline{\beta}+\Delta \beta} \frac{N(N+1)-2}{2 N(N+1)}=\frac{1}{12}$.

- We deduce that $L \in[1.2,2.88] B$. The cost $L=1.2 B$, is computed under the ${ }^{36}$ See www.transparency.org/toolkits/2001/ccinp_ip-nepal.html. 
conservative assumptions that the maximal dispersion in production cost is $20 \%$, that the average number of bidders is 3 and that delegates are able to grab the entire benefit from capture, $B=\Delta \Pi$. It is really a lower bound. ${ }^{37}$

\section{REFERENCES}

ALKARDY, M.G. (2004), "Drivers of Compensation of Heads of Procurement Units, Supervisors, and Materials Managers in the Public Sector", Journal of Public Procurement, $4(1): 1-21$.

AURIOL, E. and J.J. LAFFONT (1993), "Regulation by Duopoly", Journal of Management ES Strategy, 3, 507-533.

AURIOL, E. (1996), "Une Note sur l'Effet d'Echantillonnage", Revue Economique, 47, $1179-1201$.

BAC, M. (1996), "Corruption and Supervision Costs in Hierarchies", Journal of Comparative Economics, 22, 99- 118.

BARRETO, A. and J. KESSLER (2004), "Latin leaders' legal escape hatch", The Washington Post, 23 May 2004.

CAMPBELL, C. (1996), "Bureaucratic Collusion Via Information Sharing", mimeo.

CARILLO , R. (2000), "Corruption in Hierarchies", Annales d'Economie et de Statistique, $59,37-62$.

DOMBERGER, S., C. HALL and E. AH LEE (1995), The Determinants of Price and Quality in Competitively Tendered Contracts." Economic Journal 105:1454-70.

\footnotetext{
${ }^{37}$ On the other hand, the upper bound, $L=2.88 B$, is computed under the assumptions that the dispersion in production cost is $20 \%$, that the average number of bidders is 7 and that delegates cut of the bribes is $5 \%$.
} 
FAROOQ, U. (2001), "Newsbeat Inside- Admiral at Sea", at www.newsline.com.pk HINDRIKS, J., M. KEEN and A. MUTHOO (1999), "Corruption, Extortion and Evasion", Journal of Public Economics, 74, 395-430.

HOEKMAN, B. (1998), "Using International Institutions to Improve Public Procurement", The World Bank Research Observer, vol. 13, no 2, August, pp. 249-69.

IIMI, A. (2003), "A new perspective: Effective Execution of Development Assistance by Auction Reforms", mimeo.

KHALIL, F. and J. LAWARREE (1994), "On Commitment and Collusion in Auditing", mimeo.

KIVISTO, T. and V-M. VIROLAINENE (2005), "Benchmarking Municipal Procurement Activities in Finland", published in Challenges in Public Procurement: An International Perspective, Edited by K. V. Thai et all, PrAcademics Press, Boca Raton, Florida. KOFMAN, F. and J. LAWARREE (1993), "Collusion in Hierarchical Agency", Econometrica, 61, 629-656.

KOFMAN, F. and J. LAWARREE (1996), "A Prisoner's Dilemna Model of Collusion Deterence", Journal of Public Economics, 59, 117- 136.

KONRAD, K. and S. SKAPERDAS (1997), "Credible Threats in Extortion", Journal of Economic Behavior \& Organization, 33, 23-39.

LAFFONT, J.J. and J. TIROLE (1993), "A Theory of Incentives in Procurement and Regulation", chap 11, 12, 13, 15, MIT Press, Cambridge, Massachusetts.

LAMBERT-MOGILIANSKY A. (1997), "Regulatory Blackmail in Procurement Relationship", mimeo.

LE MONDE (1995), "Haro sur la corruption internationale", page 11, July 51995. 
LE MONDE (1996), "Des Entrepreneurs aux petits soins pour les syndics", page 15, January 81996 .

LE MONDE (2000), "Le Testament de Jean-Claude Méry, financier occulte du RPR", September 22, pages 19-22.

LEPPAMAKI M. (2000), "Money Or Reputation- A Rational Theory of Blackmail", mimeo.

MYERSON, R.B. (1981), "Optimal Auction Design", Mathematics of Operations Research, vol 6,1 .

NBC (21 July 2000), "United States of America: Eavesdropping on corruption overseas". OECD (2002), "The Size of Government Procurement Markets".

PARK, M S, and SHIN G-C (2004), "Learning from the Award-Winning Korean Public Procurement Service", paper presented at the 89th Annual International Supply Management conference, April 2004.

SHANGAI STAR (2001), "Public accountability", 2001-11-08.

STRAUSZ, R. (1998), "Collusion and Renegotiation in a Principal-Supervisor-Agent Relationship", Journal of Eco. Theory.

THE ECONOMIST (1995), "Hard Graft in Asia", page 71, May 27th.

THE ECONOMIST (1998), "Japan. The Sniping Begins", October 24.

TIROLE, J. (1986), "Hierarchies and Bureaucracies: On the Role of Collusion in Organizations", Journal of Law, Economics and Organization, 2, 181-214.

VAKNIN S. (2004), "Public Procurement and Very Private Benefits", at www.theallineed.com/adbusiness-4/business-021.htm 